\title{
THE MEASUREMENT OF THE PULMONARY DIFFUSING CAPACITY IN THE PRESENCE OF LUNG DISEASE
}

\author{
By D. V. BATES \\ (From McGill University Clinic, Royal Victoria Hospital, Montreal, Canada)
}

(Submitted for publication September 26, 1957; accepted December 26, 1957)

Recent work $(1-4)$ has shown that the rate of pulmonary gas diffusion is abnormal in a variety of clinical conditions, and its measurement seems certain to become a necessary part of any complete evaluation of pulmonary function. The various methods of measurement so far described, whether using carbon monoxide or oxygen, are capable of providing a theoretically valid figure for the diffusing capacity in normal subjects, since in them the lung may be regarded as behaving in an approximately uniform manner. A number of papers have been published in which measurements of the rate of gas diffusion in disease have been presented. A steady state Dco technique devised by Filley, MacIntosh, and Wright (5) has been used in a study of a variety of patients with pulmonary fibrosis $(3,6)$. The oxygen method has been used in studies of sarcoidosis (7), emphysema (2), mitral stenosis (8), and a number of other conditions. The single breath modified Krogh method developed by Ogilvie, Forster, Blakemore, and Morton has been used to study selected cases of a variety of different clinical conditions (9) and one study has been reported in a small group of patients using radioactive carbon monoxide (10). A steady state CO method in which the alveolar $\mathrm{CO}$ was calculated from an assumed value of respiratory dead space has been used in an attempt to establish the value of this type of function test in the assessment of emphysema (4), and a modified CO steady state technique has been used to investigate the causes of disability in pneumoconiosis (11).

Patients in whom there is little or no inequality of gas distribution or circulation in the lung do not present a major problem, since in them it can be assumed that during a steady state, a reasonably representative estimate of the mean alveolar tension of $\mathrm{CO}$ can be obtained either by measuring the end tidal $\mathrm{CO}$ tension, or by calculating alveolar $\mathrm{CO}$ tension from the measured values of arterial carbon dioxide tension, as described by Filley,
MacIntosh, and Wright (5). When it is known, however, that there is not only unevenness of distribution of inspired gas within the lung, but imbalance between ventilation and perfusion, as in the case of emphysema, the situation is very much more complicated. It cannot be assumed that in such lungs there is any constant ratio between the surface area available for diffusion and the gas volume and ventilation of different parts of the lung. It is immediately clear that in patients in whom $\mathrm{CO}_{2}$ retention is present and in whom there is a gross unevenness of gas distribution within the lung, the meaning of any single figure for the pulmonary diffusing capacity, however determined, will be questionable. Ideally, the pulmonary diffusing capacity should be the sum of the individual diffusing capacities for each alveolus. When the perfusion, diffusion, and ventilation are varying widely throughout the lung, the true diffusing capacity will be the aggregate sum of a vast number of widely differing numbers. It seems unlikely that such a figure can ever be arrived at, since if carried to its logical conclusion it would involve measurements made on individual alveolae. It is reasonably certain that no overall number for the pulmonary diffusing capacity which is found in these complex disease states will approximate to this ideal and unobtainable figure. The problem, therefore, becomes one of attempted assessment of the meaning of individual diffusion figures, however obtained, and it is the purpose of this paper to discuss the validity of steady state measurements of pulmonary diffusing capacity in lung diseases in which there is known to be gross unevenness in relation to perfusion and ventilation within the lung. Although it is not possible, for obvious reasons, to calibrate any particular method against a theoretical ideal figure, enough data have been collected to permit discussion of the significance of the results found in a number of different diseases. In particular, it is possible to estimate the significance 


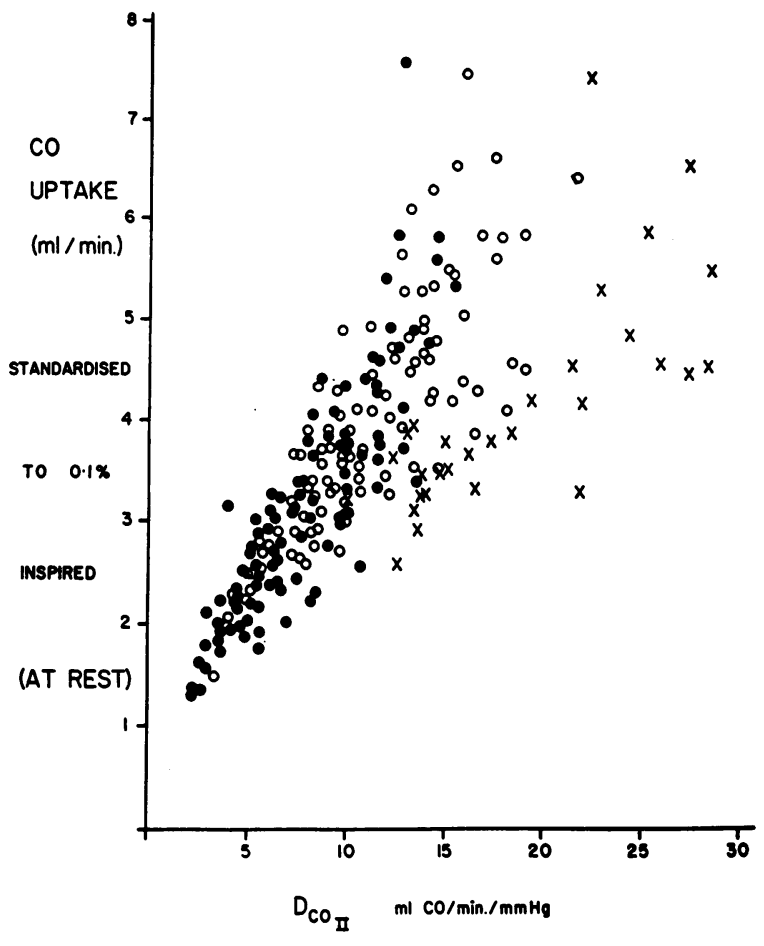

Fig. 1 (a). Relationship Between the CO Uptake Standardized to a Constant Inspired Gas Percentage (0.1 Per Cent CO) and the Pulmonary Diffusing Capacity Calculated from an End Tidal Sample (DCOII)

Although there is a general relationship between these two observations it is clear that the diffusing capacity could not be adequately calculated from the rate of uptake of carbon monoxide alone. All subjects studied at rest.

$X=$ normal subjects; $O=$ patients with normal gas mixing; $=$ patients with uneven gas mixing [helium mixing efficiency below 50 per cent (13)].

of the results obtained using a steady state carbon monoxide method, which is undoubtedly the simplest method of measurement to use.

\section{METHODS}

The technique used for the measurement of the pulmonary diffusing capacity has already been described (12). The original circuit has been modified by the addition of a photoelectric relay to open the electromagnetic valve at the end tidal sampling position. The light to the photocell is interrupted by a vane in the transparent plastic tube on the inspiratory side of the mouthpiece. An electronic timer is thus actuated by the beginning of inspiration and opens the end tidal electromagnetic valve for any chosen time period. In this way the volume of the end tidal sample can be varied, and is independent of tidal volume.

The subdivisions of lung volume have been measured on a closed helium circuit as previously described (13). The arterial $\mathrm{pCO}_{2}$ has been calculated from the $\mathrm{pH}$ measured on a Beckman $\mathrm{pH}$ meter at $37.5^{\circ} \mathrm{C}$., and total $\mathrm{CO}_{2}$ content measured on a Van Slyke apparatus.

A small respiratory circuit was built so that an end tidal sample could be taken during quiet breathing of room air during the simultaneous collection of a resting arterial blood sample. The design of this was exactly similar to the circuit used for the measurement of the pulmonary diffusing capacity, but the end tidal gas was passed through a Cambridge differential catharometer, the calibration of which had previously shown that the $\mathrm{CO}_{2}$ concentration could be read to approximately 0.05 per cent. The formulae used in the calculations are given in the Appendix.

\section{RESULTS}

The results obtained are shown in Figures 1 to 3 and may be conveniently described under various subheadings :

\section{Rest}

In a preceding communication (12), it was pointed out that in normal subjects at rest the calculation of a mean alveolar $\mathrm{CO}$ using an assumed value of respiratory dead space is liable to be grossly in error. This fact was appreciated by Krogh and Krogh (14), and is the result of the sensitivity of the Bohr equation at low tidal volumes to changes in the assumed dead space value. If, however, the rate of $\mathrm{CO}$ uptake in $\mathrm{ml}$. per minute is grossly reduced, as it is in emphysema for instance (15), this error becomes less important, and an estimate of gas diffusion can be made in patients of this type even when an assumed value of dead space is used, provided the limitations of this type of measurement are clearly recognized.

In Figure 1 (a), the $\mathrm{CO}$ uptake, standardized to a constant inspired concentration of 0.1 per cent, has been plotted against the $\mathrm{Dco}_{\mathrm{II}}$ (diffusing capacity calculated from measured end tidal $\mathrm{CO}$ concentration). It will be realized that the numerator of a fraction is plotted against the numerator divided by the mean alveolar $\mathrm{CO}$ concentration. It is clear from this graph that the resting diffusing capacity cannot be judged with any accuracy from the rate of uptake of $\mathrm{CO}$. A figure of $11 \mathrm{ml}$. CO per minute per $\mathrm{mm}$. $\mathrm{Hg}$ may be taken as aproximately the lower limit of normal for a resting Dco by this technique $(5,12)$. 
On the basis of this figure a resting uptake of less than $2.5 \mathrm{ml}$. CO per minute at an inspired concentration of 0.1 per cent might be taken to indicate considerable impairment of diffusing capacity at rest. The rate of uptake of $\mathrm{CO}$ at rest is, however, greatly influenced by ventilation (15) and thus a demonstrably abnormal diffusing capacity may exist in someone with a rate of uptake of $\mathrm{CO}$ as high as about $4.0 \mathrm{ml}$. CO per minute per $\mathrm{mm}$. Hg. A similar graph [Figure 1 (b)] of the relationship between the fractional alveolar removal of $\mathrm{CO}$, based on an assumed value for the respiratory dead space and the $\mathrm{Dco}_{\mathrm{II}}$, shows a wider scatter of results, and there is no reason to suppose that this index offers any advantage over the Dco II.

\section{Exercise}

It has been generally realized that when on exercise the tidal volume exceeds about $800 \mathrm{ml}$., the calculation of concentration of mean alveolar gas from the Bohr equation becomes relatively insensitive to any chosen value for respiratory dead space. In a previous communication (12), it was shown that in young normal subjects, on moderate exertion, the diffusing capacity calculated from an end tidal sample did not differ greatly from the diffusing capacity found if the mean alveolar $\mathrm{CO}$ was calculated from an assumed dead space value. It was expected that the good general relationship between the diffusing capacity calculated by either of these techniques would break down in conditions in which the lung was ceasing to behave as a uniform system. Figure 2 shows the relationship between these two measurements on 151 patients suffering from a variety of respiratory conditions and 24 normal subjects. The volume of respiratory dead space has been taken to correspond with the body weight in pounds (16). Every estimate made over an 18 month period has been included in this and subsequent figures. The good general agreement between the $\mathrm{Dco}_{\mathrm{I}}$ (calculated from the Bohr equation, using an assumed value of respiratory dead space) and $\mathrm{Dco}_{\mathrm{II}}$ (calculated from the measured end tidal sample) can be seen. From the point of view of assessment of pulmonary function, it is clear that on exercise either of these methods might be used without much influencing the esti- mation of degree of abnormality. It is of particular interest that there is no evidence of greater discrepancy between these two calculated values of diffusing capacity in patients known to have uneven gas distribution in the lungs (Figure 2, solid circles) than there is in patients in whom the index of helium mixing was normal (Figure 2, open circles). The general agreement between these two indices does not, of course, indicate that either of them is a correct measurement of the "ideal" pulmonary diffusing capacity. It does mean that under conditions of exercise the mean alveolar CO may either be calculated from an assumed dead space value, or directly measured from an end tidal sample, and that even if gas

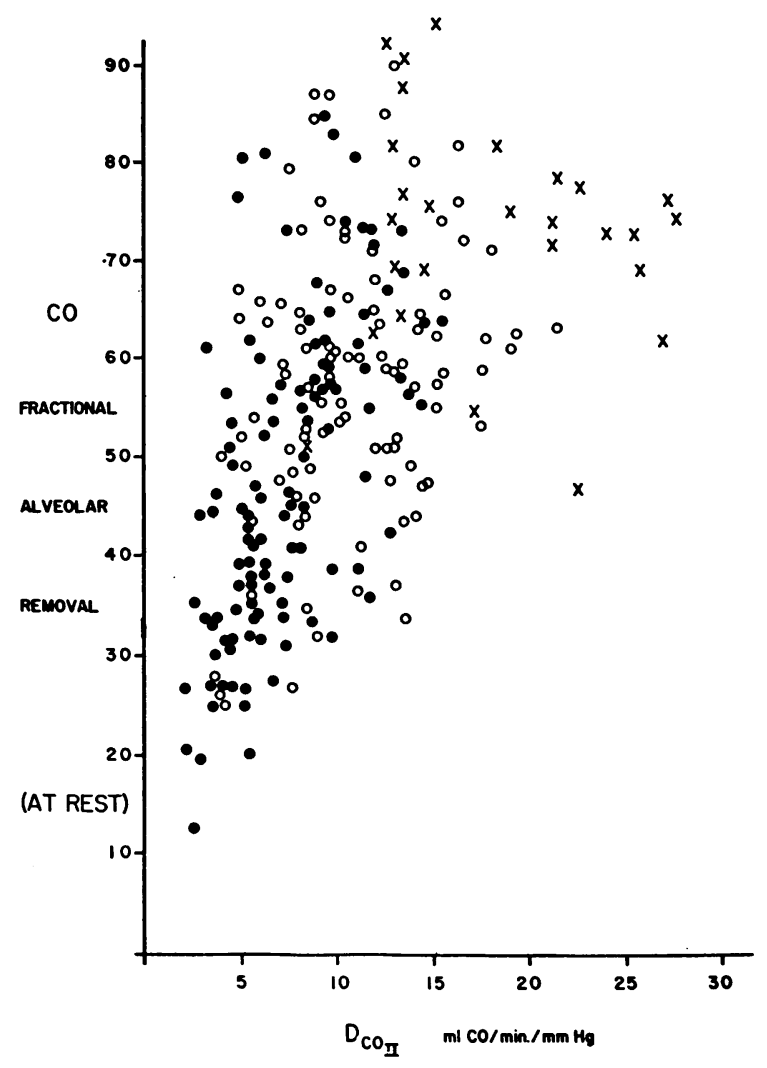

Fig. 1 (в). Relationship Between the Fractional Alveolar Removal of CO and the Pulmonary Diffusing Capacity Calculated from an End Tidal SAmple (DcOiI)

An assumed value of respiratory dead space calculated from the patient's weight has been used in computing the fractional CO removal. All subjects studied at rest. The sensitivity of the calculation of fractional removal to the assumed value of dead space makes this figure of little use in assessment of abnormality. 


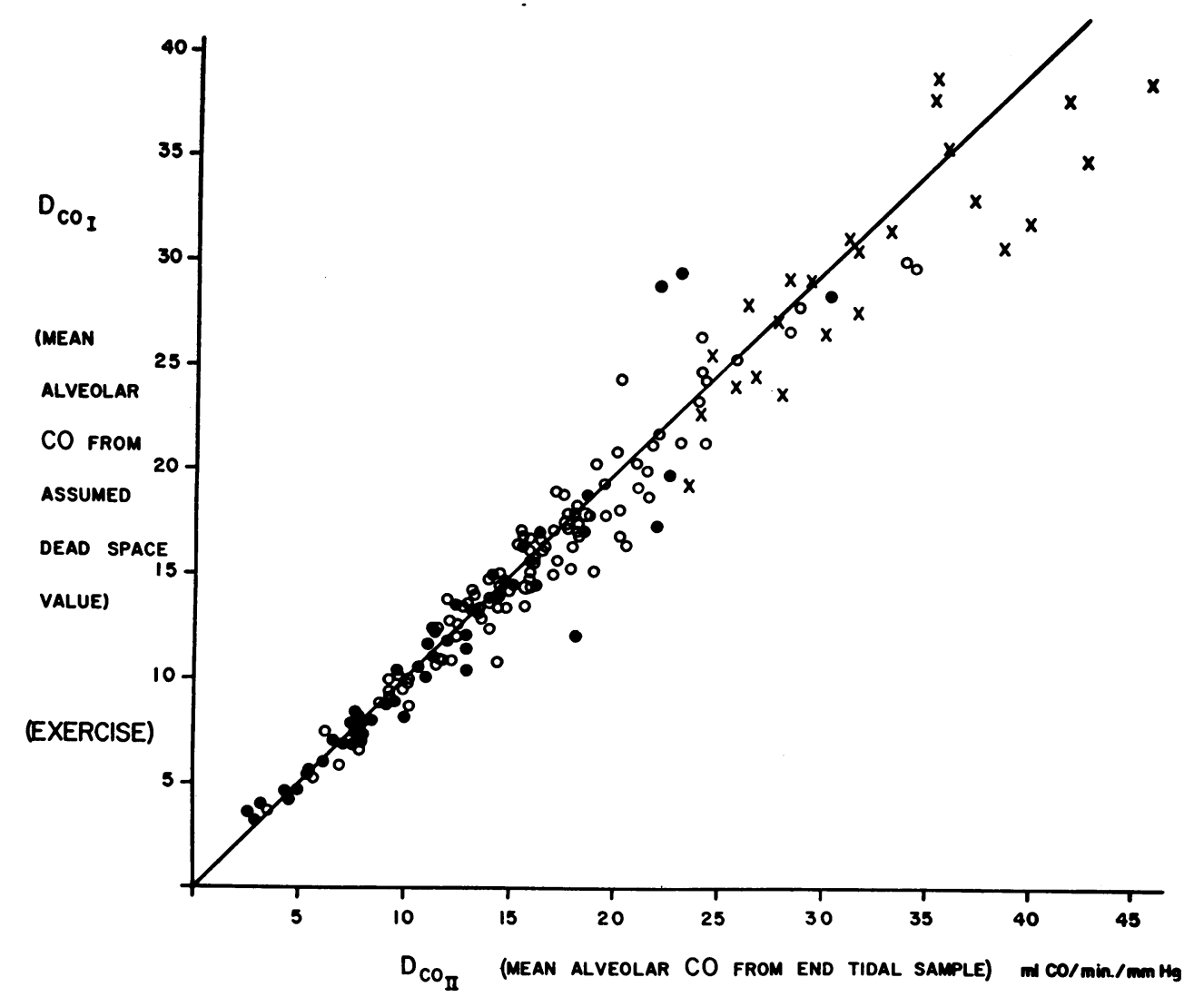

Fig. 2. Relationship Between the Pulmonary Diffusing Capacity Calculated from an Assumed Value for Respiratory Dead Space (Ordinate) and the Pulmonary Diffusing Capacity Calculated from an End Tidal Sample (Abscissa)

All observations made during exercise, and tidal volume in each case exceeding $800 \mathrm{ml}$. Results on 24 normal subjects and 151 patients [symbols as in Figure 1 (a)]. The close relationship between the two values for the diffusing capacity can be seen, and in particular there appears to be no evidence that the presence of uneven gas distribution causes any greater discrepancy between these observations than when the gas distribution is within normal limits.

distribution is uneven in the lung it will make very little difference to the calculated diffusing capacity which of these two techniques is used. There are three possible reasons for this. The first, already mentioned, is that if the tidal volume is large, errors in the assumed dead space value have little effect on the calculated mean alveolar $\mathrm{CO}$ concentration. The second possible reason for the general agreement shown in Figure 2 is that even in emphysema there may be no gross variation in $\mathrm{CO}$ concentration in different parts of the expiration under these conditions. Ogilvie, Forster, Blakemore, and Morton (9) have recently reported that using the single breath Dco technique, the calculated Dco in six normal subjects and two patients with emphysema was very little influenced by whether an "early" or "late" alveolar sample had been taken. The data in Figure 2 support this finding, since if the end tidal $\mathrm{CO}$ concentration were to be grossly different from the mean alveolar $\mathrm{CO}$, this discrepancy would show itself by more' variation and probably a systematic difference between the ordinate and the abscissa. The third reason why these two differently calculated pulmonary diffusing capacities do not show any wide variation, even in the presence of uneven gas distribution, is that the main determinant of an impaired pulmonary diffusing capacity on exercise, when measured with carbon monoxide and the steady state method, is the grossly impaired rate of uptake of the gas. It is important to remember that the calculated dif- 
fusing capacity is the rate of uptake in $\mathrm{ml}$. per minute divided by the mean alveolar carbon monoxide. In patients with impaired diffusion for any reason, the numerator of this fraction, that is, the rate of uptake of the gas in ml. a minute, is the major factor responsible for producing a low figure for the diffusing capacity, and the relative changes in the bottom of the fraction, which is the mean alveolar $\mathrm{CO}$, become decreasingly important.
This is illustrated in Figure 3 (a), which is similar to Figure 1 (a) except that all the observations were made during exercise. The general relationship between these two observations is better during exercise than at rest, and it appears that when the diffusing capacity is significantly impaired, this fact could be detected with fair precision by measuring the rate of uptake of carbon monoxide only under these conditions. For instance, on any exercise it may be taken that

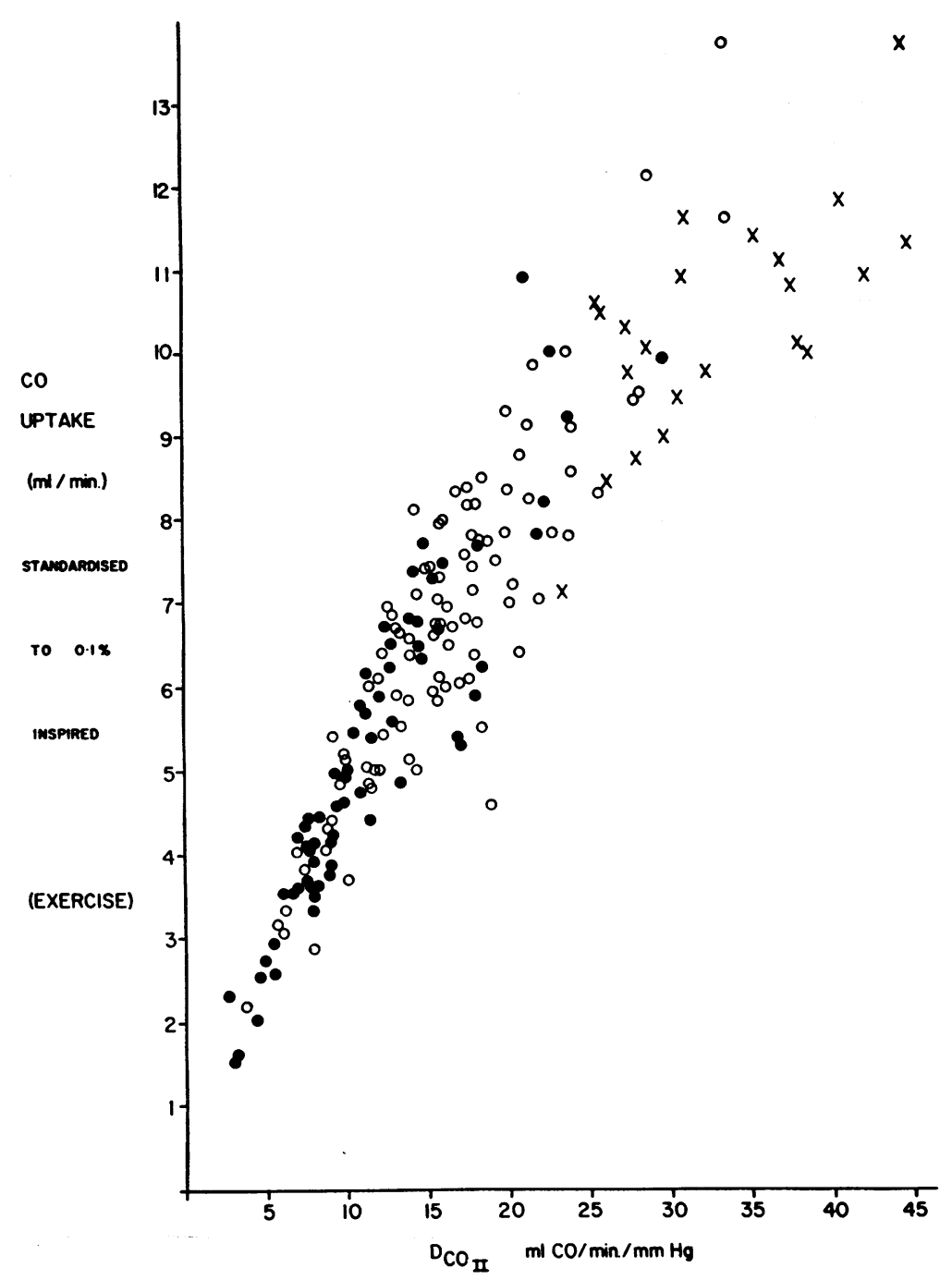

Fig. 3 (a). Relationship Between CO Uptake Standardized to 0.1 Per Cent Inspired and Dcoir Calculated from an End Tidal Sample DURING EXERCISE

Symbols as in Figures 1 and 2. On exercise there is a close relationship between these two variables and an abnormal pulmonary diffusing capacity on exercise could be predicted with fair accuracy from the measured rate of $\mathrm{CO}$ uptake alone. 
a $\mathrm{DcO}_{\mathrm{II}}$ of less than $20 \mathrm{ml}$. CO per minute per $\mathrm{mm}$. $\mathrm{Hg}$ is likely to be abnormal $(5,12)$, and it can be seen from Figure 3 that a rate of uptake of about $6.25 \mathrm{ml}$. of $\mathrm{CO}$ per minute on exercise approximately corresponds with this Dco value. The absolute rate of uptake of carbon monoxide in ml. per minute with a similar inspired concentration of $\mathrm{CO}$ was found by Filley and co-workers (5) to vary from $6.8 \mathrm{ml}$. per minute to $19.5 \mathrm{ml}$. per minute in the normal subjects studied on exercise. From Figures 2 and 3 it may be concluded, firstly, that in patients with pulmonary disease it makes little difference to the calculated Dco on exercise whether the Bohr equation be used to calculate the mean alveolar $\mathrm{CO}$, or whether an end tidal sample be taken. This correspondence applies equally to patients with normal and abnormal gas distribution in the lung. Secondly, there is a close relationship between the rate of uptake of $\mathrm{CO}$ and the $\mathrm{Dco}_{\mathrm{II}}$ on exercise, and the rate of uptake alone might be used as a test of normality of the lung. The fractional removal of $\mathrm{CO}$ calculated on an assumed value of respiratory dead space shows some general relationship to the

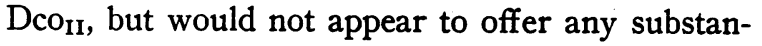
tial advantage over it [Figure 3 (b)].

Further experimental results are shown in Tables I to III. The data in Table I have been compiled from observations made during simultaneous end tidal $\mathrm{CO}_{2}$ measurements and arterial puncture. On theoretical grounds, the end tidal $\mathrm{CO}$ diffusing capacity ( $\mathrm{Dco}_{\mathrm{II}}$ ) is likely to differ from that calculated from the arterial $\mathrm{CO}_{2}$ by the greatest amount when there is a very large difference between the end tidal $\mathrm{CO}_{2}$ tension and the arterial $\mathrm{pCO}_{2}$. This $\mathrm{pCO}_{2}$ difference has been measured by Saxton and Wolter (17) in patients with emphysema, and a mean value of $8 \mathrm{~mm}$. $\mathrm{Hg}$ was found in 11 patients studied. That the patients in Table I represent severe examples of this type of condition may be judged from the fact that the difference between end tidal and arterial $\mathrm{pCO}_{2}$ (Column 8) was in no patient lower than $18 \mathrm{~mm}$. $\mathrm{Hg}$, and in one was as high as $27 \mathrm{~mm}$. $\mathrm{Hg}$. An estimate of the diffusing capacity at rest immediately preceded these observations, and

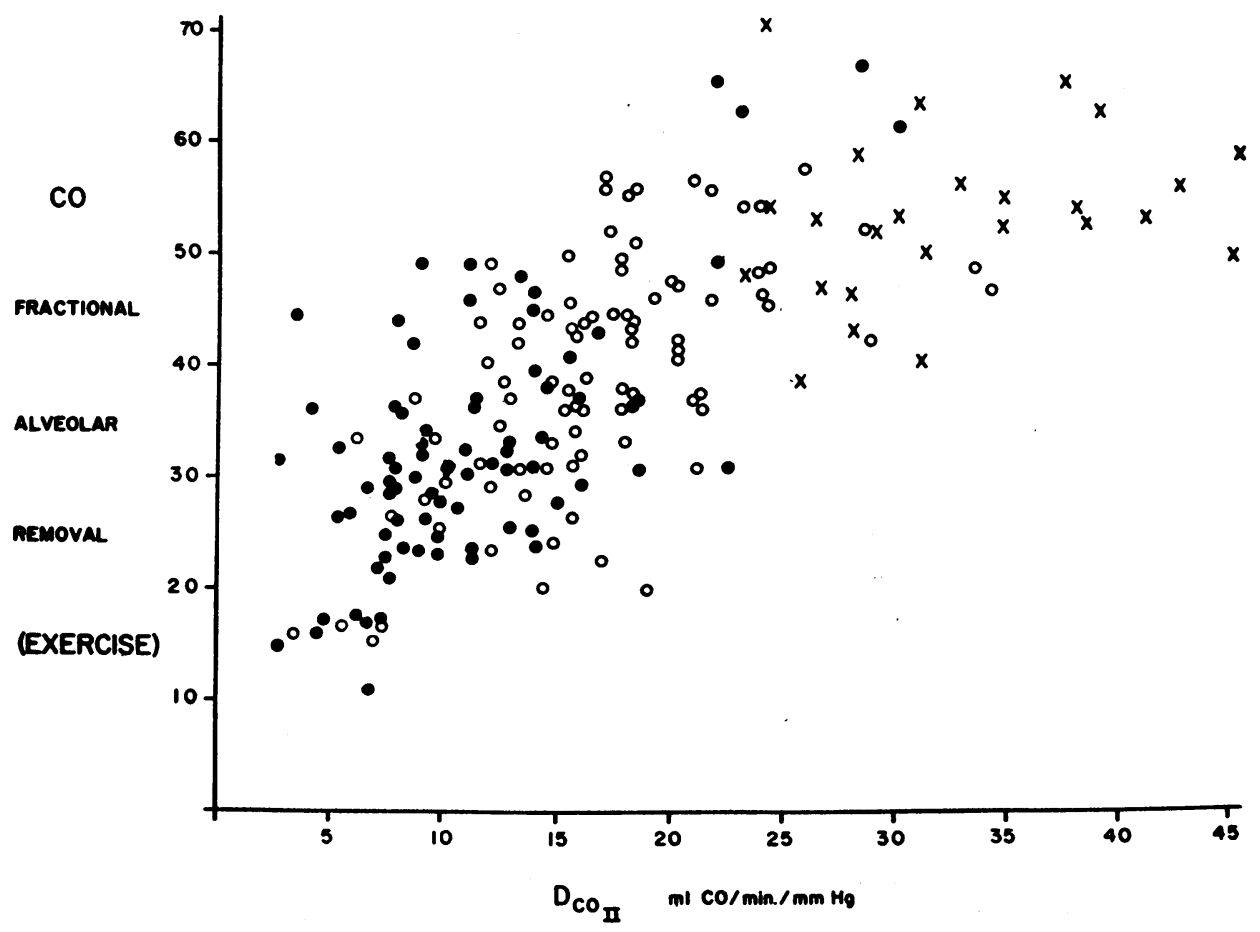

Fig. 3 (B). Relationship Between the Fractional Alveolar Removal of CO and the Pulmonary Diffusing Capacity Calculated from an End Tidal Sample (Dcoir)-All Patients Were Studied in Exercise

The fractional CO removal is in general reduced during exercise, since the level of ventilation increases proportionately more than the increase in diffusing capacity. 
PULMONARY DIFFUSING CAPACITY IN LUNG DISEASE

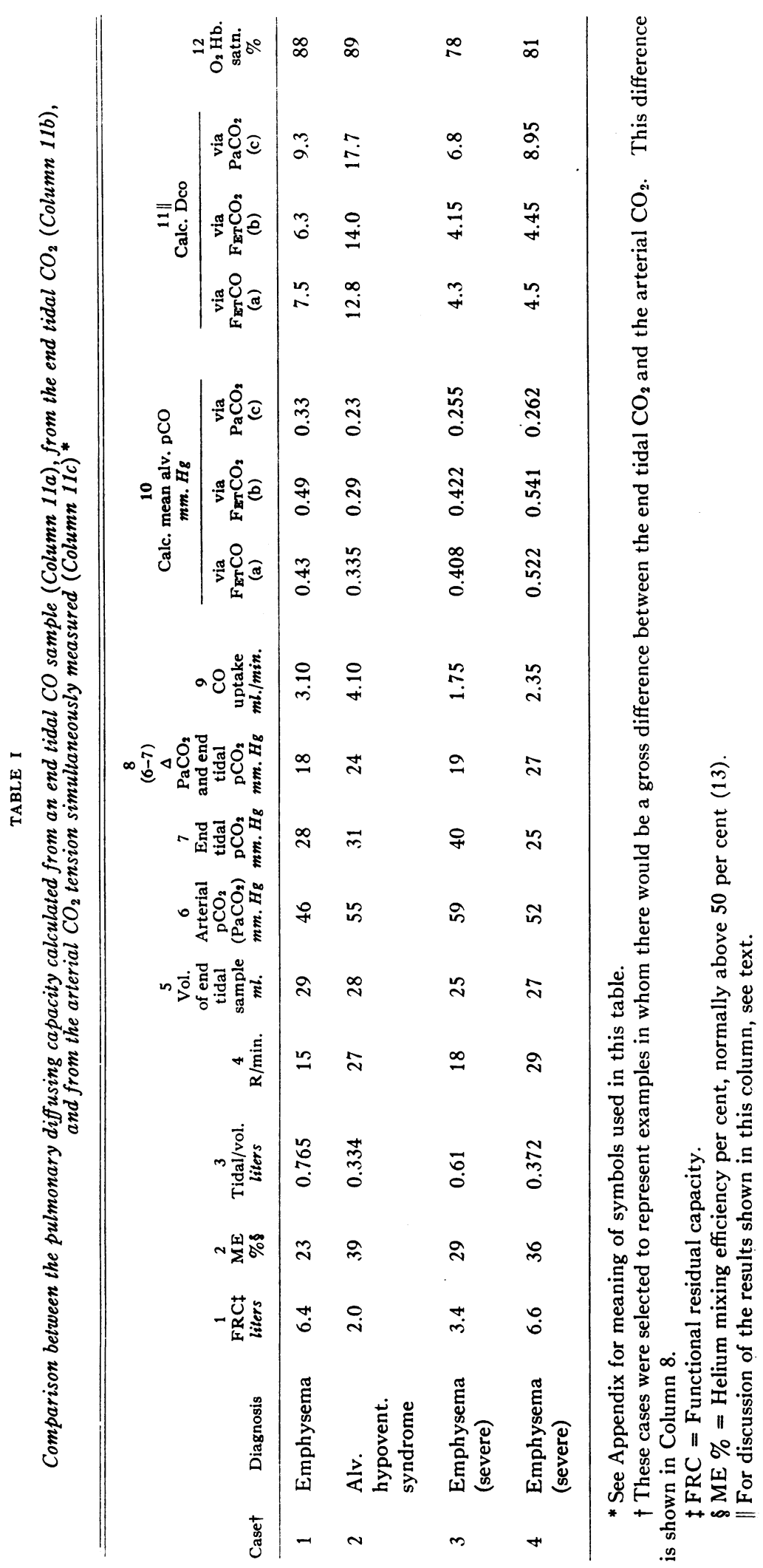


TABLE II

Analysis of the results of measurements of the pulmonary diffusion capacity during maximal exercise in four patients with emphysema and three with proven Hamman and Rich fibrosis

\begin{tabular}{|c|c|c|c|c|c|c|c|c|c|}
\hline Case & Diagnosis & $\underset{\substack{\mathbf{H e} \\
\text { mixing } \\
\text { efficiency } \\
\%}}{\stackrel{1}{\%}}$ & $\begin{array}{c}2 \\
\text { Exercise } \\
\text { (flat) } \\
m p h\end{array}$ & $\begin{array}{c}\mathrm{O}_{2} \\
\text { uptake } \\
\text { liters } / \text { min. }\end{array}$ & $\begin{array}{l}\mathbf{4} \\
\text { Min. } \\
\text { vol. } \\
\text { liters }\end{array}$ & $\stackrel{5}{\mathrm{DCOI}^{*}}$ & $\begin{array}{c}6 \\
\text { DcoII }\end{array}$ & $\begin{array}{c}\mathrm{7}^{7} \\
\left(1.23 \times \mathrm{Do}_{2}\right. \\
\text { Dcorr }\end{array}$ & $\begin{array}{c}8 \\
\text { Mean } \\
\text { gradient } \\
\left(\mathrm{O}_{2} \div \mathrm{Doz}\right) \dagger \\
\mathrm{mm} . \mathrm{Hg}\end{array}$ \\
\hline $\begin{array}{l}1 \\
2 \\
3 \\
4 \\
5\end{array}$ & $\begin{array}{l}\text { Emphysema } \\
\text { Emphysema } \\
\text { Emphysema } \\
\text { Emphysema } \\
\text { Diffuse interstitial }\end{array}$ & $\begin{array}{l}30 \\
25 \\
40 \\
30 \\
49\end{array}$ & $\begin{array}{l}1 \frac{1}{2} \\
1 \frac{1}{2} \\
2^{\frac{3}{4}} \\
2\end{array}$ & $\begin{array}{l}0.94 \\
0.77 \\
0.41 \\
0.74 \\
0.58\end{array}$ & $\begin{array}{l}28.0 \\
22.5 \\
14.7 \\
18.2 \\
21.0\end{array}$ & $\begin{array}{r}12.5 \\
7.1 \\
4.7 \\
10.1 \\
4.5\end{array}$ & $\begin{array}{r}13.9 \\
7.3 \\
4.9 \\
10.2 \\
4.6\end{array}$ & $\begin{array}{c}17.1 \\
8.97 \\
6.04 \\
12.5 \\
5.65\end{array}$ & $\begin{array}{c}55.0 \\
85.8 \\
68.0 \\
59.5 \\
102\end{array}$ \\
\hline 6 & $\begin{array}{l}\text { Diffuse interstitial } \\
\text { fibrosis (severe) }\end{array}$ & 67 & 2 & 1.06 & 28.6 & 5.5 & 6.8 & 8.36 & 126 \\
\hline 7 & $\begin{array}{l}\text { Diffuse interstitial } \\
\text { fibrosis (severe) }\end{array}$ & 46 & 2 & 1.23 & 32.0 & 8.7 & 8.8 & 10.8 & 113 \\
\hline
\end{tabular}

* There is no major discrepancy between the Dcor, calculated from an assumed value of respiratory dead space, and the Dco II calculated from an end tidal sample. All subjects breathing air during these estimations.

$\dagger$ In Column 8 is shown the mean gradient that results from converting the $\mathrm{Dco}$ to the $\mathrm{Do}_{2}$, and dividing it into the oxygen uptake simultaneously measured. Note that the mean gradients so calculated in Column 8 in the cases of Hamman and Rich syndrome arejimpossibly large. See text for discussion of this finding.

combining the data, the Dco may be calculated three ways: first, by using the measured end tidal CO (Column 11a); secondly, by using the measured end tidal $\mathrm{CO}_{2}$ in the Filley calculation (Column 11b); and, thirdly, by the Filley calculation using the measured arterial $\mathrm{pCO}_{2}$ (Column 11c). The results in Column 11a and Column $11 \mathrm{~b}$ should be the same if the gas analyses are correct, and if there is no gross difference between the behavior of the lung in respect of diffusion and perfusion. It can be seen from Table I that agreement between Columns 11a and $11 \mathrm{~b}$ is close. It is apparent, however, that there may be differ- ences between the Dco calculated from the end tidal $\mathrm{CO}$ or $\mathrm{CO}_{2}$ (Column 11a and b) and that measured by the Filley method (Column 11c). These are exemplified by Case 4 in which one figure was double the other. Yet in Patient 3, in whom the gas mixing defect is as severe (Column 2 ), and the $\mathrm{PCO}_{2}$ differences considerable (Column 8), the difference between the two measured diffusing capacities is much less. The order of difference in these patients, though considerable on a percentage basis, would not produce any great discrepancy in the assessment of pulmonary function, though examples might well be found

TABLE III

Comparison between function test results in six patients with spasmodic asthma and in eight with pulmonary emphysema

\begin{tabular}{|c|c|c|c|c|c|c|c|c|c|c|c|c|c|}
\hline \multicolumn{7}{|c|}{ Asthma } & \multicolumn{7}{|c|}{ Emphysema } \\
\hline Case & Sex & Age & FRC & ME \% & $\begin{array}{l}\text { MBC (a) } \\
\text { or max. } \\
\text { midexp. } \\
\text { f. r. (b)** } \\
\text { (\% predicted) }\end{array}$ & $\begin{array}{c}\text { Resting } \\
\text { DcoII } f\end{array}$ & Case & Sex & Age & FRC & ME \% & $\begin{array}{c}\text { MBC (a) } \\
\text { or max. } \\
\text { midexp. } \\
\text { f. r. (b)* } \\
\text { (\% predicted) }\end{array}$ & $\begin{array}{c}\text { Resting } \\
\text { Dcont }\end{array}$ \\
\hline $\begin{array}{l}1 \\
2 \\
3 \\
4 \\
5 \\
6\end{array}$ & $\begin{array}{l}\mathrm{F} \\
\mathrm{M} \\
\mathrm{M} \\
\mathrm{M} \\
\mathrm{F} \\
\mathrm{M}\end{array}$ & $\begin{array}{l}22 \\
24 \\
30 \\
42 \\
44 \\
48\end{array}$ & $\begin{array}{l}3.5 \\
5.4 \\
3.4 \\
3.1 \\
3.1 \\
3.6\end{array}$ & $\begin{array}{l}45 \\
24 \\
37 \\
15 \\
40 \\
50\end{array}$ & $\begin{array}{r}61 \text { (b) } \\
5 \text { (b) } \\
21 \text { (b) } \\
31 \text { (a) } \\
40 \text { (b) } \\
31 \text { (b) }\end{array}$ & $\begin{array}{l}17.5 \\
26.1 \\
13.7 \\
12.8 \\
22.0 \\
26.0\end{array}$ & $\begin{array}{r}7 \\
8 \\
9 \\
10 \\
11 \\
12 \\
13 \\
14\end{array}$ & $\begin{array}{l}\mathbf{M} \\
\mathbf{M} \\
\mathbf{M} \\
\mathbf{M} \\
\mathbf{M} \\
\mathbf{M} \\
\mathbf{M} \\
\mathbf{M}\end{array}$ & $\begin{array}{l}48 \\
52 \\
63 \\
64 \\
68 \\
60 \\
69 \\
64\end{array}$ & $\begin{array}{l}6.4 \\
5.1 \\
3.2 \\
5.5 \\
4.7 \\
3.3 \\
4.5 \\
4.7\end{array}$ & $\begin{array}{l}24 \\
50 \\
28 \\
41 \\
25 \\
27 \\
22 \\
43\end{array}$ & $\begin{array}{c}7.5 \text { (b) } \\
44 \text { (a) } \\
11 \text { (b) } \\
4.2 \text { (b) } \\
11 \text { (b) } \\
15 \text { (b) } \\
8 \text { (b) } \\
17 \text { (b) }\end{array}$ & $\begin{array}{l}7.5 \\
5.7 \\
5.9 \\
6.1 \\
7.5 \\
6.6 \\
7.9 \\
5.7\end{array}$ \\
\hline \multicolumn{2}{|c|}{ Mean values } & 35 & 3.7 & 35 & 31 & 19.7 & & & 61 & 4.67 & 32.5 & 15 & 6.6 \\
\hline
\end{tabular}

* Per cent predicted maximal breathing capacity or maximal midexpiratory flow rate.

$\dagger$ Although the gas distribution defect, as shown by the mixing efficiency (ME \%), and the ventilatory defect as shown by one or other of the ventilatory tests, are similar in these two conditions, the resting Dconc calculated from the end tidal sample is very much lower in emphysema than in asthma. See text for discussion of significance of this difference. Maximal midexpiratory flow rate measured by Leuallan's technique (34). 
in which the differences were large enough to influence the assessment made.

From the point of view of interpretation, the difference between these measurements may be summarized as follows :

1. End tidal Dco. Provided that the volume of the end tidal sample is controlled, and provided that the patient's respiratory dead space has been flushed, this will represent the Dco of the predominantly ventilated lung.

2. Dco calculated from arterial $p C O$. Since relatively unventilated but perfused lung (areas of potential diffusion) causes a rise in the arterial $\mathrm{pCO}_{2}$, this Dco may be thought of as including a component of potentially useable lung surface area which may be "available" only in a limited way for purposes of oxygen transfer.

It is known that in emphysema, at the end of a long period of nitrogen washout breathing oxygen, a deep breath will often produce a peak of nitrogen showing that certain parts of the lungs were not being ventilated at all during ordinary quiet respirations (18). The same phenomenon has been demonstrated by pressure volume studies of the lung which suggest that in this disease there is trapped gas in the lung not taking any part of normal ventilatory exchange (19). The diffusing capacity measured from the arterial $\mathrm{CO}_{2}$ will include a component influenced by such areas of lung, whereas that measured from an end tidal sample will not include any such part. It is obviously impossible to say which is the correct Dco unless it is specified whether one is including unventilated lung in that definition.

A further check on the measured Dco II figure may be obtained by simultaneous estimation of the oxygen uptake and diffusing capacity during exercise. Using the factor of 1.23 to convert the $\mathrm{Dco}_{\text {II }}$ to the $\mathrm{Do}_{2}$, the usual equation may be rearranged:

Mean gradient $=\frac{\mathrm{O}_{2} \text { uptake L. } / \mathrm{min}}{(\mathrm{mm} . \mathrm{Hg})}$

(mean alveolar $\mathrm{O}_{2}$ pressure minus mean capillary $\mathrm{O}_{2}$ pressure).

When the patient is breathing air $\left(\mathrm{pO}_{2}\right.$ equals 140 $\mathrm{mm} . \mathrm{Hg}$ ), the mean gradient cannot possibly be higher than about $90 \mathrm{~mm}$. Hg. Donald, Renzetti, Riley, and Cournand, who have made many indirect measurements of this value for the cal- culation of the $\mathrm{Do}_{2}$, find it to average between 40 $\mathrm{mm}$. $\mathrm{Hg}$ and $60 \mathrm{~mm}$. $\mathrm{Hg}(1)$, and it seems impossible on theoretical grounds that this mean gradient could exceed $90 \mathrm{~mm}$. $\mathrm{Hg}$. When the Dco II $_{\text {II }}$ and the oxygen uptake are simultaneously measured, a falsely low $\mathrm{Dco}_{\text {II }}$ in respect of the observed oxygen uptake would be revealed by the finding of an impossibly high mean gradient. In a recently completed study (20) of 26 patients with pulmonary sarcoidosis in different stages, the diffusing capacity was measured by the end tidal sampling technique during exercise, and the $\mathrm{O}_{2}$ uptake was simultaneously estimated. The calculated mean gradients on exercise ranged from $28.4 \mathrm{~mm}$. $\mathrm{Hg}$ to $89.0 \mathrm{~mm}$. $\mathrm{Hg}$, with a mean of $49.0 \mathrm{~mm}$. Hg. These patients had no evidence of uneven gas distribution in the lungs. Similar measurements have been recorded by Cugell, Marks, Ellicott, Badger, and Gaensler (3) using the Filley technique and studying patients with pulmonary fibrosis without gas distribution defects. In their group of 23 patients, the mean gradients similarly calculated from the recorded Dco and oxygen uptake range from $24.9 \mathrm{~mm} . \mathrm{Hg}$ to $88.4 \mathrm{~mm}$. $\mathrm{Hg}$, with a mean of $55.2 \mathrm{~mm}$. $\mathrm{Hg}$. These general figures are remarkably similar and suggest that in this group of diseases it matters little which technique is used to measure the mean alveolar $\mathrm{CO}$. In other exercise studies using end tidal sampling on patients with thyrotoxicosis, anemia, polycythemia, and a wide variety of other clinical conditions, the calculated mean gradients appear to be within reasonable limits (21).

Table II shows this type of calculation in seven patients. The first four were suffering from established emphysema, and the level of exercise they achieved represented nearly the maximum possible for them. All the patients were noted to be very dyspneic after this exercise, and although no attempt was made to train them to even higher rates of effort, it may be taken that they were working nearly at the highest level they could achieve. The diffusing capacity was measured simultaneously with the oxygen uptake. In the final column the calculated mean gradients are shown. It is not, of course, possible to fix an absolute upper limit to the mean gradient under these circumstances, but it seems likely that a mean gradient of $85 \mathrm{~mm}$. $\mathrm{Hg}$, as recorded in the second patient, might be taken as definitely indi- 
cating that the Dco as measured must have been too low. The last three patients in Table II were all suffering from a fibrosis of the Hamman and Rich type, the diagnosis in each case being confirmed by lung biopsy. It will be seen that in them there was only minimal defect in gas mixing, and it may be taken that the distribution of alveolar gas was very little impaired in these patients. In spite of this, the diffusing capacity, which in each of these patients was measured twice, when converted to the $\mathrm{Do}_{2}$ and divided into oxygen uptake, produces a number for the mean gradient which appears to be far higher than it could reasonably be with the patient breathing air. In the case of $\mathrm{Pa}$ tient No. 6, for instance, when the inspired oxygen tension was only $140 \mathrm{~mm}$. $\mathrm{Hg}$, the mean gradient was $126 \mathrm{~mm}$. Hg. There is probably some explanation why this condition gives rise to this aberrant figure on this type of calculation, and it is of interest that it appears to be the only condition capable of doing so. There is no gross disturbance of gas distribution in these subjects, and hence there is no reason to suppose that there is any great discrepancy between the end tidal $\mathrm{CO}_{2}$ and arterial $\mathrm{CO}_{2}$. It is possible that there is a $\mathrm{CO}_{2}$ gradient in this disease between alveoli and pulmonary capillary blood, yet this should not affect the calculated $\mathrm{Dco}_{\text {II }}$ which, on the basis of end tidal sampling, should still be capable of giving a correct figure for the mean alveolar $\mathrm{CO}$. The difficulty might be arising, however, because the conversion factor from $\mathrm{Dco}$ to $\mathrm{Do}_{2}$ may be incorrect in this disease. Theoretically, the abnormal cells causing the thickening of alveolar walls characteristic of the Hamman and Rich syndrome might be more permeable to oxygen than to carbon monoxide, and if this were the case the error in the calculation lies in the conversion of the Dco to the $\mathrm{Do}_{2}$. If, in Patient No. 6 of Table II, the conversion factor from $\mathrm{Dco}$ to $\mathrm{Do}_{2}$ should be 1.84 and not 1.23 , the mean gradient would be reduced from $126 \mathrm{~mm}$. $\mathrm{Hg}$ to $85 \mathrm{~mm}$. $\mathrm{Hg}$, a figure that might be acceptable. A second and more likely explanation is that if the abnormal cells in the lung are metabolizing oxygen to any great extent, then the rate of oxygen uptake as a whole would be an overestimate of the amount of oxygen diffusing through the barriers in the lung. In the case of the three patients in Table II, one would have to postulate that the lung cells were taking up 86,350 , and $313 \mathrm{ml} . \mathrm{O}_{2}$ per minute to explain the falsely high gradients on this basis, and it seems unlikely that the oxygen uptake of the lung tissue could be as high as these figures. Neither of these explanations can be regarded as satisfactory, and the finding of an apparently absurdly. high mean gradient in this condition must be confirmed in similar cases before its significance can be assessed.

In Table III, six cases of asthma are compared to eight cases of emphysema and the striking difference in the Dco's found in these two groups is illustrated. It is possible in asthma to have a considerable mixing defect and ventilatory defect and yet have a normally preserved diffusing capacity at rest (Case 2), and in emphysema there may be fairly good preservation of ventilatory function and a borderline normal figure for evenness of gas mixing, and yet considerable abnormality in the calculated diffusing capacity (Case 8 ). The clinical selection of these subjects is not a simple matter. The cases of emphysema shown in Table III were clinically advanced cases with constant effort dyspnea and a preceding long history of chronic bronchitis. Previously recorded experience has shown that advanced cases of emphysema may be selected with reasonable certainty by these criteria (4). The patients in the asthma group had all been followed for many years in the allergy department. In all of them there was evidence of seasonal bronchospasm due to allergic sensitivity, and in none was there constant effort dyspnea. This table serves to illustrate the fact that the level of the diffusing capacity found by end tidal sampling with subjects at rest is not inevitably influenced by the evenness of gas distribution, and is certainly capable of discriminating between these two conditions by the difference in diffusing capacity between them. This is well illustrated by a comparison between the setond patient and the tenth. With similar functional residual capacities and ventilatory impairment, and the mixing defect greater in the patient with asthma, the Dco II in the asthmatic was $26.1 \mathrm{ml}$. $\mathrm{CO}$ per minute per $\mathrm{mm}$. $\mathrm{Hg}$, and in the patient with emphysema it was only $6.1 \mathrm{ml}$. CO per minute per $\mathrm{mm}$. Hg. Tomograms of the lungs of these two patients showed a normal small vessel pattern in the asthmatic, and a great loss of peripheral pulmonary vessels in the patient with 
emphysema. In spasmodic asthma, if the degree of bronchospasm is so severe that the patient is only ventilating a very small volume of the lung, a slight reduction in diffusing capacity may be found, but it is not reduced to the levels seen in patients with advanced emphysema.

\section{DISCUSSION}

The theoretical considerations governing the validity of measurements of the pulmonary diffusing capacity have been discussed in detail by Forster, Fowler, and Bates (22). If the pulmonary diffusing capacity is to be defined as the sum of the diffusing capacities of each alveolus, it is clear that no measurement of it that is "rigorously correct" can be made when there is variation of diffusion within the lung. All contemporary methods of measurement depend on estimating the rate of gas uptake, either over a timed interval of breath holding or during a steady state experiment, and dividing this by a calculated mean pressure of the gas. No "overall" measurement made in this way can claim to necessarily represent the correct overall diffusing capacity of the lungs. The "limitations" imposed on the various methods of measurement may be summarized as follows:

\section{A. Methods using carbon monoxide}

(a) Uncertainty whether Dco can be converted to $\mathrm{Do}_{2}$ under all circumstances of disease, particularly in the Hamman and Rich syndrome (see results above).

(b) Interference of $\mathrm{COHb}$ in the blood (23). Possibility of local back pressure effect in the plasma due to slow passage of $\mathrm{CO}$ into the red cell (24).

(c) Single breath method $(3,9)$

1. Measurement influenced by ratio of diffusion to contained gas volume in the lung (22).

2. Assumption that total rate of uptake of the gas during held breath can be calculated from held portion of gas expired may be false in some cases.

3. Uncertainty whether the lung in a single held breath is typical of the lung during steady state conditions.

\section{(d) Steady state methods}

1. Filley method $(3,5,6)$. Use of arterial $\mathrm{pCO}_{2}$ may lead to a higher estimated Dco than is "available" to the patient for oxygen transfer; probably approximates to the highest likely Dco.

2. End tidal sampling method (12). This represents the diffusing capacity of predominantly ventilated lung. At rest is bound to be lower than the Filley Dco in the presence of $\mathrm{CO}_{2}$ retention. A small end tidal sample is essential to avoid dead space contamination which would cause a falsely low figure. On exercise the Dco calculated from the end tidal sample agrees closely with that calculated from an assumed value of respiratory dead space even in the presence of unequal gas distribution in the lung (Figure 2).

(e) All steady state methods are influenced by the ratio between the distribution of ventilation and diffusion within the lung ( 7 , 22).

(f) $\mathrm{C}^{14} \mathrm{O}$ method (25) represents a compromise between $(c)$ and $(d)$ above. Factors influencing it are difficult to assess.

\section{B. Oxygen method (26)}

(a) Note that this method avoids difficulties of $A(a),(b)$ and $(c)$ above.

(b) Uncertainty of effect of hypoxia on the rate of diffusion through the lung.

(c) Overall measurement may be falsely low under pathological conditions (27).

In view of these many uncertainties it is remarkable that similar results have been reported in different diseases using these different methods. Table IV shows some of the results so far reported in three pathological conditions. It is not possible to make detailed comparisons between the results obtained by different authors, since in many cases inadequate clinical details are provided to enable one to judge the severity of the cases studied. When these problems are remembered, the general agreement shown in Table IV leads to the suggestion that although all methods of measuring the pulmonary diffusing capacity in disease may be subject to error, the 
TABLE IV

Comparison between results obtained by different authors of measurements of the pulmonary diffusing capacity in three diseases

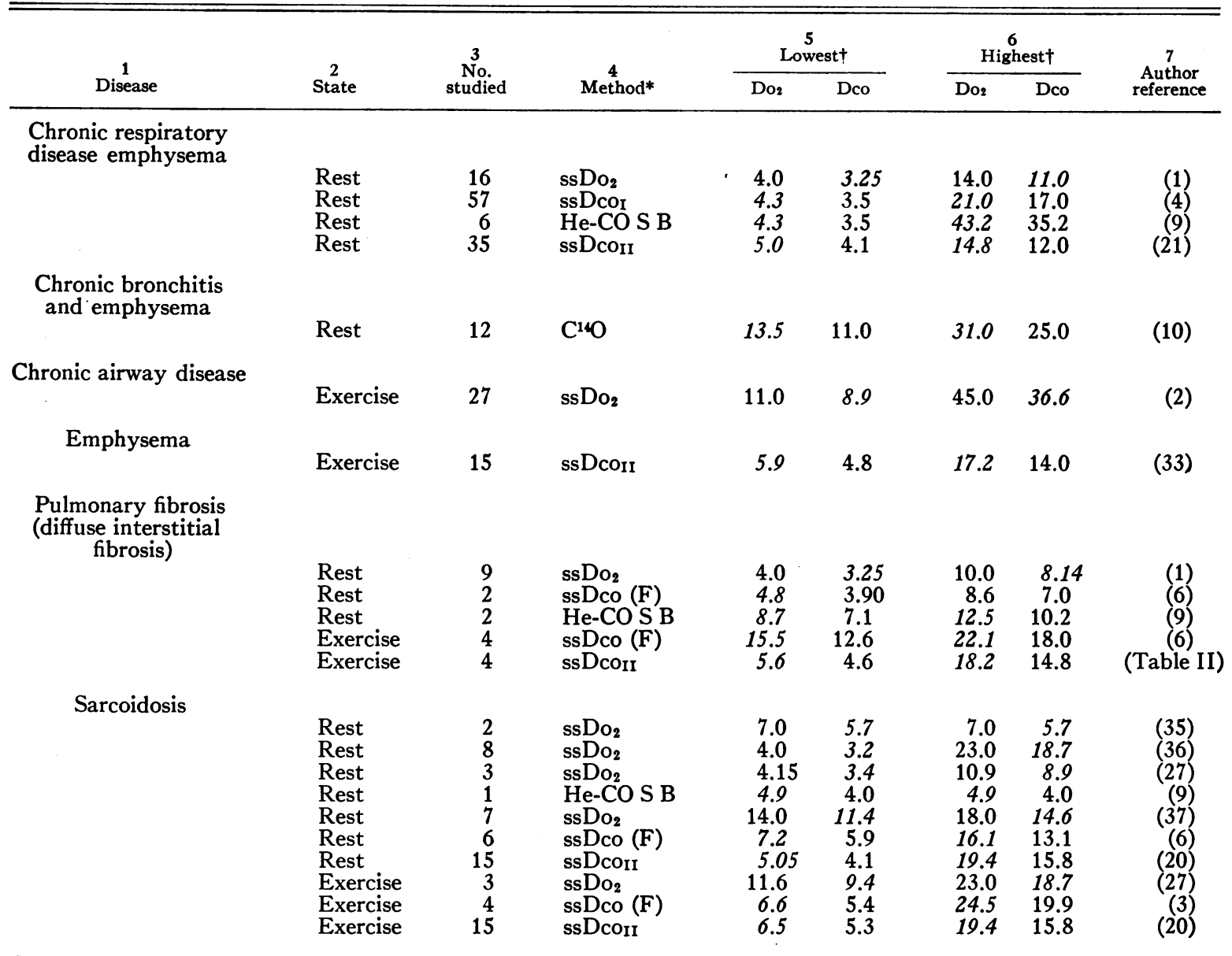

${ }^{*} \mathrm{ssDo}_{2} \quad=$ Steady state oxygen method.

He-CO S B = Modified Krogh single breath method.

ssDco $(\mathrm{F})=$ Steady state CO technique using arterial $\mathrm{pCO}_{2}$.

ssDcor $=$ Steady state $\mathrm{CO}$ technique assuming value for respiratory dead space.

ssDcoII = Steady state $\mathrm{CO}$ technique using measured end tidal $\mathrm{CO}$ concentration.

$\mathrm{C}^{14} \mathrm{O}=$ Radioactive $\mathrm{CO}$ method.

$\dagger$ The actual measurement is shown in standard type, and the computed equivalent Dco or $\mathrm{Do}_{2}$ is shown in italics.

same errors are in general affecting all the methods to a similar degree.

In Table III a comparison was made between the function test results found in spasmodic asthma and emphysema. It is evident from this table that although the ventilatory defect in these two conditions may be very similar, as it was in Patients No. 2 and 10 in Table III, the diffusing capacities as measured by the end tidal sampling technique may be widely different. This indicates almost certainly the preservation of a normal lung parenchyma in asthma on the one hand, and its destruction as the essential lesion of pulmonary emphysema on the other. This differentiation has recently received support from a number of different observations. Gough (28) has stressed the pathological differences between the two conditions, and the radiological differences have been emphasized by Hornykiewytsch and Stender (29) from a study of postmortem specimens. The loss of a normal pulmonary arterial pattern in emphysema has also recently been demonstrated by angiocardiograms (30). The findings shown in Table III are of interest because they illustrate the fact that although in two conditions there may be a gross unevenness of gas distribution and con- 
siderable ventilatory defect, yet the diffusing capacity measured by the end tidal sampling technique is able to distinguish between them. It has been suggested (31) that function tests might be combined to make a "discriminant function" capable of a more precise diagnosis of emphysema. This may well be found to be the case; but it is important to recognize the possibility that one function test, in this instance carbon monoxide, may be capable of a far greater discrimination between two conditions such as asthma and emphysema than any combination of other tests.

All those who have used the pulmonary diffusing capacity in the assessment of lung function have become convinced of its value. Cugell, Marks, Ellicott, Badger, and Gaensler (3), and Marks, Cugell, Cadigan, and Gaensler (6) have pointed out the importance of this measurement in the proper analysis of patients with pulmonary fibrosis. The loss of diffusing surface after pneumonectomy has been shown to be one of the factors contributing to residual disability (32). Shepard, Cohn, Cohen, Armstrong, Carroll, Donoso, and Riley (2) have shown that the measurement of the pulmonary diffusing capacity in chronic obstructive disease of the airways puts a different perspective on the syndrome of chronic bronchitis and emphysema, since the loss of lung parenchyma that occurs in emphysema may take place with relatively insignificant bronchitis, and this change may not be evident without a measurement of the pulmonary diffusing capacity. There is also some evidence that the measurement of pulmonary diffusing capacity is of value in assessing the prognosis of pulmonary emphysema (4). In view of this preliminary evidence, it is obviously necessary that continuing critical attention be devoted to the methods used in its measurement.

The use of a "maximal diffusing capacity" introduced by Riley appeared to be a useful concept with the $\mathrm{Do}_{2}$ technique. It has not been possible, however, to demonstrate a consistent plateau of diffusing capacity with the carbon monoxide methods $(12,24)$, and it seems likely that the hypoxia involved in the $\mathrm{Do}_{2}$ method may be responsible for the constant finding of a maximal value with that technique.

There can be no doubt that the steady state carbon monoxide technique is the simplest of all existing methods to use. The single breath $\mathrm{CO}$ method requires accurate helium analyses in the presence of varying $\mathrm{CO}_{2}$ concentrations, and has the additional disadvantage of being inapplicable in a dyspneic patient during exercise. Since the normal subject increases the pulmonary diffusing capacity considerably on exercise, the difference between normal and abnormal lungs is greatly accentuated by exercise studies. All patients should be studied during exercise if possible, since not only are the method errors reduced by the increased tidal volume it produces, but the discrimination between normal and abnormal is sharpened. These advantages have been stressed in a number of recent studies of gas diffusion $(2,3,20,32,33)$.

\section{SUMMARY}

1. Data collected during estimates of the pulmonary diffusing capacity on 151 patients have been analysed to clarify the validity of the end tidal sampling method of measuring the mean alveolar CO concentration in lung disease. It has been shown that during exercise there is good correspondence between the Dco calculated from such samples, and the Dco estimated by using the Bohr equation to compute a value for the mean alveolar CO concentration.

2. On exercise, measurement of the rate of uptake of $\mathrm{CO}$ alone would be sensitive enough to use in the assessment of abnormality in pulmonary diffusion. This measurement would not be adequate under resting conditions.

3. Comparisons between the Dco calculated from the arterial $\mathrm{pCO}_{2}$ and the Dco calculated from the measured end tidal $\mathrm{CO}$ concentration show that the former is probably measuring a "highest likely" Dco and the latter probably the Dco of predominantly ventilated lung.

4. Evidence is presented that suggests that the steady state Dco measured during exercise in patients with the Hamman and Rich syndrome of diffuse pulmonary fibrosis cannot be correctly converted to the $\mathrm{Do}_{2}$ by the use of the usual conversion factor.

5. A comparison of results obtained with the end tidal sampling technique in patients with asthma and emphysema indicates that the use of carbon monoxide in these two conditions enables an estimate to be made of the relative normality of the lung parenchyma. 
6. In spite of the many contemporary uncertainties in the measurement of the pulmonary diffusing capacity by any technique, the general form of reported results in three different lung diseases suggests that all methods are giving an approximately similar range of results. This probably indicates that all available methods are being influenced in the same direction by similar causes of error.

\section{ACKNOWLEDGMENTS}

I wish to thank Dr. J. A. P. Pare for his assistance in the collection of arterial blood samples, and Dr. R. V. Christie whose encouragement of this work has made its continuation possible.

\section{APPENDIX}

Symbols: $\mathrm{D}_{\mathrm{co}}=$ Diffusing capacity $(\mathrm{CO})$ in ml. per minute per $\mathrm{mm} . \mathrm{Hg}$

$\mathrm{P}_{\mathrm{b}}=$ Barometric pressure, $\mathrm{mm} . \mathrm{Hg}$

$\mathrm{V}_{\mathbf{T}}=$ Tidal volume

$\mathrm{R}=$ Respirations per minute

$V_{D}=$ Dead space (includes instrumental dead space

$\left.\begin{array}{rl}F_{I} & =\text { Inspired } \\ F_{E X} & =\text { Mixed expired } \\ F_{E T} & =\text { End tidal }\end{array}\right\} \begin{gathered}\text { Carbon monoxide con- } \\ \text { centration ATPD }\end{gathered}$

(a) $\mathrm{D}_{\text {coI }}$ calculated from an assumed value of the respiratory dead space:

$D_{\text {coI }}=\frac{V_{T}\left(V_{T}-V_{D}\right) \times R \times\left(F_{I}-F_{E X}\right)}{\left(F_{E X} V_{T}-F_{I} V_{D}\right) \times\left(P_{b}-47\right)} \mathrm{ml} . / \mathrm{min} . / \mathrm{mm} . \mathrm{Hg}$.

(b) $\mathrm{D}_{\text {coII }}$ calculated on the assumption that the end tidal sample represents the mean alveolar tension:

$$
\mathrm{D}_{\text {coII }}=\frac{\mathrm{V}_{\mathrm{T}} \times \mathrm{R} \times\left(\mathrm{F}_{\mathrm{I}}-\mathrm{F}_{\mathrm{EX}}\right)}{\mathrm{F}_{\mathrm{ET}} \times\left(\mathrm{P}_{\mathrm{b}}-47\right)} \mathrm{ml} . / \mathrm{min} . / \mathrm{mm} . \mathrm{Hg} .
$$

(c) Fractional alveolar removal was calculated as follows: Fractional alveolar removal

$$
=\frac{V_{T} \times R \times\left(F_{I}-F_{E X}\right)}{F_{I} \times R \times\left(V_{T}-V_{D}\right)} \times 100 \% .
$$

(d) $\mathrm{D}_{\mathrm{co}}(\mathrm{F})$ was calculated using the simultaneously measured arterial $\mathrm{pCO}_{2}$ to compute the mean alveolar $\mathrm{CO}$ tension as described by Filley, MacIntosh, and Wright (5).

\section{REFERENCES}

1. Donald, K. W., Renzetti, A., Riley, R. L., and Cournand, A. Analysis of factors affecting concentrations of oxygen and carbon dioxide in gas and blood of lungs: Results. J. appl. Physiol. 1952, 4, 497.

2. Shepard, R. H., Cohn, J. E., Cohen, G., Armstrong, B. W., Carroll, D. G., Donoso, H., and Riley, R. L. The maximal diffusing capacity of the lung in chronic obstructive disease of the airways. Amer. Rev. Tuberc. 1955, 71, 249.
3. Cugell, D. W., Marks, A., Ellicott, M. F., Badger, T. L., and Gaensler, E. A. Carbon monoxide diffusing capacity during steady exercise. Amer. Rev. Tuberc. 1956, 74, 317.

4. Bates, D. V., Knott, J. M. S., and Christie, R. V. Respiratory function in emphysema in relation to prognosis. Quart. J. Med. 1956, n. s. 25, 137.

5. Filley, G. F., MacIntosh, D. J., and Wright, G. W. Carbon monoxide uptake and pulmonary diffusing capacity in normal subjects at rest and during exercise. J. clin. Invest. 1954, 33, 530.

6. Marks, A., Cugell, D. W., Cadigan, J. B., and Gaensler, E. A. Clinical determination of the diffusion capacity of the lungs. Amer. J. Med. 1957, 22, 51.

7. Riley, R. L., Riley, M. C., and Hill, H. McD. Diffuse pulmonary sarcoidosis: Diffusing capacity during exercise and other lung function studies in relation to ACTH therapy. Bull. Johns Hopk. Hosp. 1952, 91, 345.

8. Riley, R. L., Johns, C. J., Cohen, G., Cohn, J. E., Carroll, D. G., and Shepard, R. H. The diffusing capacity of the lungs in patients with mitral stenosis studied post-operatively. J. clin. Invest. 1956, 35, 1008.

9. Ogilvie, C. M., Forster, R. E., Blakemore, W. S., and Morton, J. W. A standardized breath holding technique for the clinical measurement of the diffusing capacity of the lung for carbon monoxide. J. clin. Invest. 1957, 36, 1.

10. Kjerulf-Jensen, K., and Kruh $\phi$ ffer, P. The lung diffusion coefficient for carbon monoxide in patients with lung disorders, as determined by $\mathrm{C}^{14} \mathrm{O}$. Acta. med. scand. 1954, 150, 395.

11. Gilson, J. C., and Hugh-Jones, P. Lung function in coalworkers pneumoconiosis. Spec. Rep. Ser. No. 290 med. Res. Coun. (Lond.), 1955.

12. Bates, D. V., Boucot, N. G., and Dormer, A. E. The pulmonary diffusing capacity in normal subjects. J. Physiol. (Lond.) 1955, 129, 237.

13. Bates, D. V., and Christie, R. V. Intrapulmonary mixing of helium in health and in emphysema. Clin. Sci. 1950, 9, 17.

14. Krogh, A., and Krogh, M. On the rate of diffusion of carbonic oxide into the lungs of man. Skand. Arch. Physiol. 1910, 23, 236.

15. Bates, D. V. The uptake of carbon monoxide in health and in emphysema. Clin. Sci. 1952, 11, 21.

16. Radford, E. P. Ventilation standards for use in artificial respiration. J. appl. Physiol. 1955, 7, 451.

17. Saxton, G. A., Jr., and Wolter, J. Non-uniform distribution of blood and gas in lungs in pulmonary disease. Fed. Proc. 1957, 16, 112.

18. Vosti, K. L., Pearson, J., Saxton, G., Lepper, M., and Dowling, H. F. Pulmonary function in bronchiectasis. Clin. Res. Proc. 1957, 5, 228.

19. Bedell, G. N., Marshall, R., DuBois, A. B., and Comroe, J. H., Jr. Plethysmographic determina- 
tion of the volume of gas trapped in the lungs. J. clin. Invest. 1956, 35, 664.

20. Marshall, R., Smellie, H., Baylis, J. H., Hoyle, C., and Bates, D. V. Pulmonary function in sarcoidosis. In press.

21. Bates, D. V.' Unpublished data.

22. Forster, R. E., Fowler, W. S., and Bates, D. V. Considerations on the uptake of carbon monoxide by the lungs. J. clin. Invest. 1954, 33, 1128.

23. Linderholm, H. On the significance of $\mathrm{CO}$ tension in pulmonary capillary blood for determination of pulmonary diffusing capacity with the steady state CO method. Acta med. scand. 1957, 156, 413.

24. Forster, R. E. Exchange of gases between alveolar air and pulmonary capillary blood. Pulmonary diffusing capacity. Physiol. Rev. 1957, 37, 391.

25. Kruh $\varnothing \mathrm{ffer}, \mathrm{P}$. Studies on the lung diffusion coefficient for carbon monoxide in normal human subjects by means of $\mathrm{C}^{14} \mathrm{O}$. Acta physiol. scand. 1954, 32, 106.

26. Riley, R. L., and Cournand, A. Analysis of factors affecting partial pressures of oxygen and carbon dioxide in gas and blood of lungs: Theory. J. appl. Physiol. 1952, 4, 77.

27. Forster, R. E., Fowler, W. S., Bates, D. V., and Van Lingen, B. The absorption of carbon monoxide by the lungs during breath holding. J. clin. Invest. 1954, 33, 1135.

28. Gough, J. Correlation of radiological and pathological changes in some diseases of the lung. Lancet 1955, I, 161.
29. Hornykiewytsch, Th., and Stender, H. S. Die gefässveränderungen bei Emphysem und Pulmonalsklerose. Fortschr. Röntgenstr. 1955, 82, 642.

30. DeClercq, F., DeCoster, A., Bollaert, A., Denolin, H., and Englert, M. Aspects angiopneumographiques de l'emphyseme pulmonaire diffus. Acta tuberc. belg. 1956, 47, 194.

31. Gilson, J. C., and Oldham, P. D. Lung function tests in the diagnosis of pulmonary emphysema Proc. roy. Soc. Med. 1952, 45, 584.

32. Mcllroy, M. B., and Bates, D. V. Respiratory function after pneumonectomy. Thorax 1956, 11, 303.

33. Bates, D. V. Gas diffusion and lung function in Pulmonary Circulation and Respiratory Function: A Symposium Held at Queen's College, Dundee. Edinburgh, E. \& S. Livingstone, 1956, p. 33.

34. Leuallan, E. C., and Fowler, W. S. Maximal midexpiratory flow. Amer. Rev. Tuberc. 1955, 72, 783.

35. Austrian, R., McClement, J. H., Renzetti, A. D., Jr., Donald, K. W., Riley, R. L., and Cournand, A. Clinical and physiologic features of some types of pulmonary diseases with impairment of alveolarcapillary diffusion. Amer. J. Med. 1951, 11, 667.

36. McClement, J. H., Renzetti, A. D., Himmelstein, A., and Cournand, A. Cardiopulmonary function in the pulmonary form of Boeck's sarcoid and its modification by cortisone therapy. Amer. Rev. Tuberc. 1953, 67, 154.

37. Williams, M. H., Jr. Pulmonary function in Boeck's sarcoid. J. clin. Invest. 1953, 32, 909. 